\title{
Students' perception of the Service Quality Gaps of Omantel Company using SERVQUAL Model
}

Ikhlas Abdullah Al-Shibli' ${ }^{1}$, AlSafa Rashid Al-Mamari ${ }^{2}$, Hiba Hamed Al-Dhahri ${ }^{3}$

Faculty of Business, Sohar University, Sohar, Oman

Email: ${ }^{1}$ Eklas94@outlook.com ${ }^{1}$ ㄹlsafa_almamari@outlook.com, ${ }^{3}$ H3hiba13@ hotmail.com

Article History: Received on 24 $4^{\text {th }}$ Jan. 2021, Revised on $23^{\text {rd }}$ Feb. 2021, Published on $7^{\text {th }}$ Mar. 2021

\begin{abstract}
Purpose of the study: The objective of the study is to determine the impact of service quality gaps in the telecommunications industry in Oman, through critically analysing the differences between the expectations and perceptions in relates to tangibility, empathy, reliability, responsiveness, and assurance.

Design/Methodology/Approach: The study used the SERVQUAL model to calculate the existing quality of service of the telecommunication company operating in the Sultanate of Oman and to know the differences between expectations and perceptions of the quality of services provided to the customers by Omantel Company. The sampling used in this study was convenient sampling adopted through a questionnaire where the size of the sample was 150 which was randomly selected from the students of different faculties at Sohar University. The data were analysed using the SPSS program.

Findings: The findings of the research study revealed that there exists a negative relationship between the customer perceptions and expectations and the difference in the scores between the two sets of variables is in favour of the expectations of the respondents in relates to Omantel services. The reliability factor had the largest difference between the two sets of variables and the tangibles factor had the smallest difference.

Research Implications: The results of this study help Omantel Company to strategically develop service quality in the areas of assurance, empathy, and responsiveness and to understand how consumers view the quality of the service, and to help the organization track and sustain quality service.

Originality/value: The research was performed in the rapidly increasing telecom service industry, which is experiencing dramatic changes over time and is making concentrated efforts to keep up with unparalleled, ground-breaking advances in technology. This research can be extended to other sectors of the market.
\end{abstract}

Keywords: Service Quality, Omantel, Telecommunications industry in Oman, SERVQUAL Model, Customers' Satisfaction, Perception and Expectations.

\section{Introduction}

Globalization has changed the business environment by introducing advanced technology, strategies, a process, and procedures that increase the performance, efficiency, and thus helping the development of the organization (Urban, 2009). Different standards are also introduced to improve the performance and quality of products within the organization.

In this era of globalization, organizations compete and supply products according to customer's requirements. Quality is the principal attractive factor for the customers and they preferred only quality-based products. Therefore, it is necessary to retain a large number of customers by offering quality products. The role of management is important in an organization that manages all activities, operations, and processes responsibly. Service quality of the product is managed through senior management and human resource management partnership.

Quality is especially important in the service industry as well as in the telecommunications sector. In the last few years, since the introduction of mobile services, the telecommunication sector has expanded massively. The telecommunication industry is performing as connecting people around the world through different ways like mobile phones, the internet, and wireless communication among people from country to country. Moreover, due to a large number of customers in the telecommunications industry, this would lead to a rise in the number of companies in the telecommunications sector which will contribute to more competition in this sector.

Technical quality refers to how well the customer is pleased with the quality of the services, while functional quality depends on the quality of the contact with the customer during the provision of services. Functional quality is taken in a broader sense as it covers the aspects of personnel behaviour while dealing with and the ethics of an organization.

In Oman, the telecommunication sector has two main companies which are Omantel and Ooredoo. Also, Vodafone is a new company that will be providing services soon in the years to come. Globalization has changed the trends in the industrial sector and some industries have become more important to contribute to the economy of a country. There is a direct relationship between business growth and the improvement telecommunication industry (Shafei \& Tabaa, 2016). The quality provided by telecom companies is the main factor that attracts customers and satisfies them. Many studies were carried out using different ways to 
analyse the service quality issues prevailing within the telecom industry of Oman (Al Jabri et al., 2017). The service quality has different measures depending upon the industry in which it is being gauged. However, customer satisfaction is the main factor in the quality of service. From the point of view of customers, the quality of service depends on their understanding of the service quality of the company and what they get as part of the services (Anjum et al., 2016).

Quality is the major leading factor that enhances the performance, productivity, and reputation of a company. The main purpose of the study was to see their dissatisfaction of service quality provided to customers by the Omantel Company. Omantel Company was established in Oman in the year 1999. This company provides wireless communication through broadband and offering 3G and 4G mobile services (Castelnovo et al., 2019). The main objective of this research was to identify and analyse the gaps in service quality in the telecommunication industry in Oman using the SERVQUAL model. SERVQUAL, an important method for determining the quality of service was used by Parasuraman, Valarie A. Zeithaml, and Len Berry ( $\underline{\text { Foster, }}$ 2000). The SERVQUAL model is used to measure the quality of service which includes five dimensions viz. tangibles, reliability, responsiveness, assurance, and empathy. This model also includes two sets of variables that are beliefs and perceptions.

The quality services of the telecommunication industry impact the productivity, performance, and financial position of the industry as well. The study deals with the main factors that give rise to the satisfaction of the customers from the services of Omantel Company. The significance of this study is to analyse all factors that contribute to the reduction of quality of services in the telecommunication industry in Oman similar to that of study carried out by Yarimoglu \& Kursunluoglu (2015). Therefore, the study primarily focused on the gap that is prevailing in the quality services of Oman telecom (Dayani et al., 2015).

\section{SERVQUAL}

Measuring the standard of quality of service has always been a difficulty. However, when the introduction of the SERVQUAL scale, it became easier to assess the quality of service in terms of expectations and perceptions. Although this quality model had been adopted by many industries, some researchers questioned its validity and reliability. This made this model weak. Therefore, an alternative model to SERVQUAL was suggested which is known as the SERVPERF model (Hosseini et al., 2013). This model, unlike the SEVQUAL five dimensions, is based on the single dimension i.e. performance. The researchers found that using performance alone in measuring the service quality rather than using expectation minus perception, yielded better results in terms of reliability and validity. However, talking about the telecommunication sector the service quality is conceptualized in different ways.

It depends upon the domain in which the services are provided, and all dimensions might be or might be not contributing to customers' satisfaction in that particular domain. For example, while using the ATM, empathy as a dimension is not relevant as a dimension of service quality. Likewise, while providing customer care service, tangibility is not important of service quality dimension. Assurance as a service quality dimension might be important in the industries of higher risks like medical and legal services. Hence, for specific services, the service quality dimensions related to those services are only important.

\section{Problem Statement}

The dimensions - tangibility, responsiveness, consistency, empathy, and reliability of service quality have a direct impact on customer satisfaction, especially in the telecommunication industry. However, it has been seen that the mobile industry is seeing a great high trend across the world. This is raising the importance of the well-established telecommunication industry. When a customer contacting the customer service of a telecom company, the customer care representative has to make sure that his communication leaves a positive impact on the customer so that he perceives good quality services from the company.

Although the telecommunication industry of Oman is performing well poor service management hurt the confidence and the satisfaction of customers, giving rise to an impact of bad reputation to the company. The Omantel Company in particular is not considering the expectations of customers as services are not up to the mark as expected from the company. Therefore, there exists a gap in quality services of the Telecom industry in Oman due to poor implementation. So, this has trigger the reason for the study.

\section{Research Questions}

The research study aims to find the answer to the following research question:

- Are there significant differences between expectations and perceptions related to tangibility, empathy, reliability, responsiveness, and assurance? 


\section{Research Objectives}

The prime objective of the study is to determine the impact of service quality gaps in the telecommunications industry in Oman. This is done through following objective of the current research, i.e.

- To identify the effect of service quality dimension on overall service quality through critically analysing the differences between the expectations and perceptions in relates to tangibility, empathy, reliability, responsiveness and assurance.

\section{Theoretical Framework}

The theoretical framework developed for the present research was based on the SERVQUAL model's five dimensions: reliability, responsiveness, tangibility, assurance, and empathy (Singh \& Kumar, 2015). Tangibility refers to the physical aspect of the services, which includes the equipment, communication tools, and the personnel handling the services. However, in the context of the telecommunication sector tangibility is not among the important dimensions. Reliability refers to the level of services promised by the organization and what is delivered accurately to the customers. It is mostly related to prices, service provision, and problem resolution. Customers prefer companies that keep up their commitments. It is therefore among the essential dimensions of the service quality. Responsiveness is correlated with the fast and timely response to the customers' requests for help. This dimension demands attentiveness and it is also among the important dimensions. Assurance is inspiring trust and confidence in the customers. It depends upon the behaviour of the employees during the service provision. Empathy is about giving undivided individual attention to the customer. Customers are becoming a focal point in modern business and catering to their demands is an utmost important aspect.

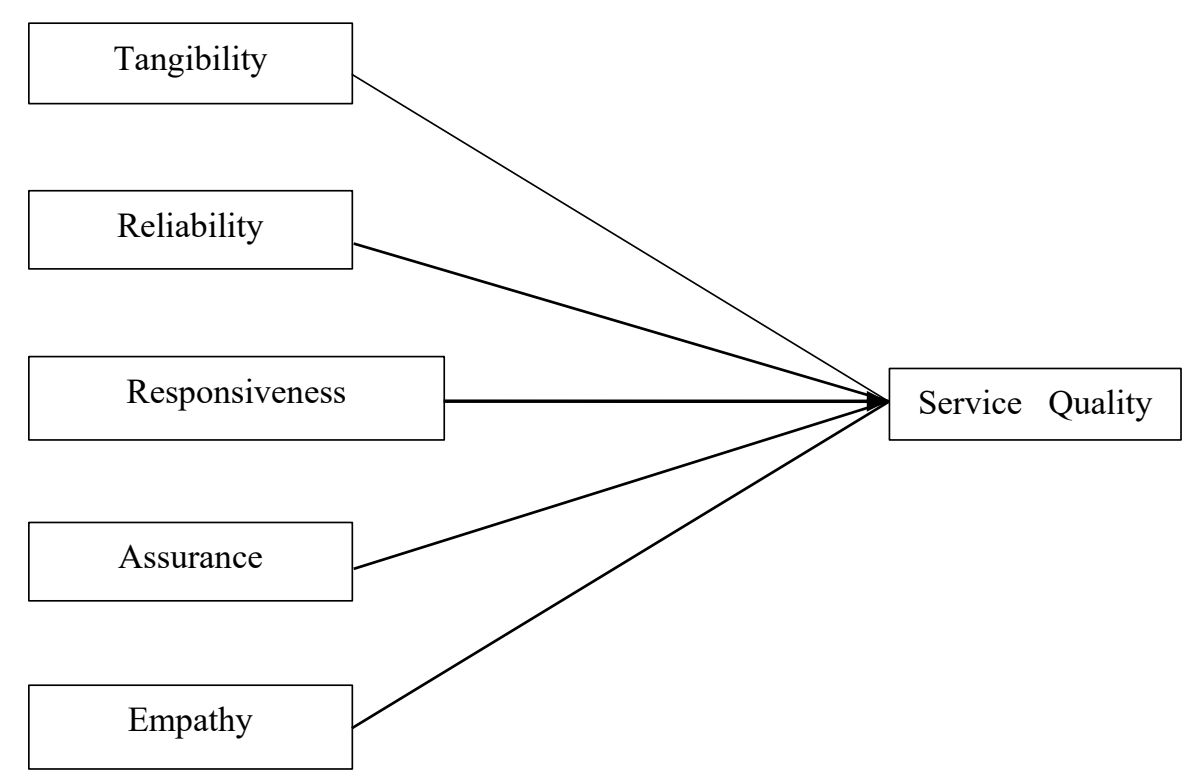

Figure 1. Five dimensions of the SERVQUAL model (Singh \& Kumar, 2015)

\section{Literature Review}

Several studies have shown that the level of quality of service affects customer retention and customer satisfaction. Described the problem that consistently exists in enterprises where the quality of products is lost due to improper management (Urban, 2009). It is hard to measure service quality because of intangible dimensions and the intangible things like services could only be perceived and it could vary from person to person (Yang, 2015). There are two distinct dimensions of quality in the telecom industry i.e. functional quality and the other is technical quality (Singh \& Kumar, 2015).

Measuring the standard of quality of service has always been a difficulty. However, when the introduction of the SERVQUAL scale, it became easier to assess the quality of service in terms of expectations and perceptions. Although this quality model had been adopted by many industries, some researchers questioned its validity and reliability. This made this model weak. Therefore, an alternative model to SERVQUAL was suggested which is known as the SERVPERF model (Hosseini et al., 2013). Many of the researchers thought 
that the evaluation of service quality by the consumers depends on the experience they have with the service providers (Olatokun \& Ojo, 2016). Such researchers eliminated the concept of multi-dimensions in measuring service quality. However, it was also developed that SERVPERF and SERVQUAL are standardized instruments for measuring the quality of service. In China, a changed modified version of the SERVQUAL instrument was used to assess the quality of service in the Chinese telecommunication sector. For the model, they added the dimension of network quality, and the research was carried among the focus group of experts in the sector (Wang et al., 2015). Their findings were based on the structural equation model, which established that the most important and authentic dimensions in measuring service quality are assurance, reliability, and network quality. However, they found no aspect of empathy and responsiveness as influential dimensions that impact the customers' satisfaction. Similar study in the telecom sector in Ethiopia in which the respondents were questioned about the additional aspect of service quality using open-ended questions (Palladan \& Ahmad, 2019).

A study by Rahhal (2015) based on three dimensions viz. compliant handling, service convenience, and network quality conducted that network quality scored the highest among the customer service dimensions. Some researchers also extended the traditional concept of service quality dimensions with added attributes such as reputation, reliability, transmission quality, competitiveness, customer support, and relational quality (Rahhal, 2015). However, it was concluded that all aspects of service quality do not automatically contribute to the satisfaction of customers (Mpwanya \& Letsoalo, 2019). In the 21st century, taking in the context of the telecommunication sector, the service quality dimensions have broadened and now six dimensions are included in the service quality: Value-added services, pricing structure, mobile devices, customer service, and the billing system (Newton \& Ragel, 2017).

Competitiveness and reliability were found to have the greatest influence on customer satisfaction. Also found that reliability and relational quality were the most important dimensions in this aspect. Following the controversial researchers' debates about service quality and customer satisfaction, it is now established that both are different phenomenon. The researchers are now of the opinion that service quality is a broader term in connection with customer satisfaction (Khan et al., 2017).

Among these service quality dimensions, the billing system, customer service, and pricing structure were found to have a significant impact on customer satisfaction, which had a positive impact on customer loyalty in Greece (Santouridis \& Trivellas, 2010). They also developed a multi-dimensional model and the hierarchical model for the dimensions of service quality. Based on that model the primary dimensions of service quality were found to be quality of the environment, quality of interaction, and quality of the result.

\section{Hypothesis}

Based on the above review of literature, the following hypothesis was derived:

- There is a significant difference between expectations and perceptions in relates to tangibility, empathy, reliability, responsiveness and assurance.

\section{Research Methodology}

The study used the SERVQUAL model to calculate the existing quality of service of the telecommunication company operating in the Sultanate of Oman and to know the differences between expectations and perceptions of the quality of services provided to the customers by Omantel Company.

Initially the research adopted a pilot survey for 20 students at Sohar University. Questionnaire was used to collect the information from the customers of Omantel about their expectations and perceptions about service quality provides by Omantel Company. The survey questionnaire was consisting of three sections: The first one included the general information about the respondent like gender, age, level of study, and faculty, etc. The second and the third sections of the questions were consisting of 22 questions each to seek the respondents' opinions about the expectations and perceptions of service quality provided by Omantel. Respondents were required to rate the statements based on their experience as to how much they believe such statements in relates to Omantel service. The 22 questions covered all the five dimensions of service quality (Foster, 2000). Statements 1 to 4 aim were designed to estimate the tangibility element of the Omantel Company. The dimensions of reliability were measured through statements 5 to 9 while the dimension of responsiveness were measured through the statements 10 to 13. The dimensions of assurance were measured 
through statements 14 to 17 and empathy was tested through 18 to 22 . The answered to the questionnaires were using a Likert scale.

The sampling used in this study was convenient sampling adopted through a questionnaire where the size of the sample was 150 which was randomly selected from the students of different faculties at Sohar University. The data was analysed using SPSS program and Microsoft Excel.

Table 1 Five dimensions of Service Quality

\begin{tabular}{|l|l|}
\hline Dimensions & Items \\
\hline Tangibles & $1-4$ \\
\hline Reliability & $5-9$ \\
\hline Responsiveness & $10-13$ \\
\hline Assurance & $14-17$ \\
\hline Empathy & $18-22$ \\
\hline
\end{tabular}

Findings

Table 2 Gender of the respondents

\begin{tabular}{|l|c|c|}
\hline Gender & Frequency & Percent \\
\hline Female & 106 & 70.7 \\
Male & 44 & 29.3 \\
\hline
\end{tabular}

Table 2 shows that the total number of respondents and their gender. The total number of participants were 150. Male participants were $29.3 \%$ of the total participants, whereas female participants were $70.7 \%$ of the total participants.

Table 3 Age of the respondents

\begin{tabular}{|c|c|c|}
\hline Age & Frequency & $\%$ \\
\hline $18-20$ & 21 & 14.0 \\
$21-23$ & 66 & 44.0 \\
$24-26$ & 39 & 26.0 \\
$27-29$ & 10 & 6.7 \\
30 and above & 14 & 9.3 \\
\hline
\end{tabular}

Table 3 demonstrates that there were 5 categories. The highest age group range was between 21 and 23 with a percentage of $44 \%$ and the least age group range of participants was between 27 and 29 with a percentage of $6.7 \%$.

Table 4 Level of study of the respondents

\begin{tabular}{|l|c|c|}
\hline Level of study & Frequency & \% \\
\hline Diploma (level 1) & 16 & 10.7 \\
Diploma (level 2) & 20 & 13.3 \\
Advanced Diploma (level 3) & 28 & 18.7 \\
Bachelor (level 4) & 77 & 51.3 \\
Master & 9 & 6.0 \\
\hline
\end{tabular}

Table 4 illustrates the different levels of study of the participants. There were five different levels of study. The majority of the number of participants was in the level 4 of Bachelor graduates with 51.3\% unlike the least frequency number of participants in the level of master graduates with a $6 \%$.

Table 5 Faculty Name of the respondents

\begin{tabular}{|l|c|c|}
\hline Level of study & Frequency & \% \\
\hline Faculty of Business & 62 & 41.3 \\
Faculty of Computing and IT & 12 & 8.0 \\
Faculty of Education and Arts & 23 & 15.3 \\
Faculty of Engineering & 22 & 14.7 \\
Faculty of Language Studies & 21 & 14.0 \\
Faculty of Law & 10 & 6.7 \\
\hline
\end{tabular}


Table 5 demonstrates the different faculties that the participants belonged to. There are six different faculties. The highest frequency numbers of participants were in the faculty of business respondents with a $41.3 \%$ whereas the least frequency number of participants is in the Faculty of Law with $6.7 \%$.

Table 6. Average of Perceptions and Expectations of Service Quality

\begin{tabular}{|c|c|c|c|c|}
\hline Factor & Item & $\begin{array}{c}\text { Perception } \\
\text { Average }\end{array}$ & $\begin{array}{c}\text { Expectation } \\
\text { Average }\end{array}$ & Differences \\
\hline \multirow{5}{*}{ Tangibles } & 1 & 5.34 & 6.013 & -0.673 \\
\hline & 2 & 5.447 & 6.193 & -0.746 \\
\hline & 3 & 5.68 & 5.687 & -0.007 \\
\hline & 4 & 5.673 & 5.833 & -0.16 \\
\hline & Average & 5.535 & 5.9315 & -0.3965 \\
\hline \multirow{6}{*}{ Reliability } & 5 & 5 & 6.22 & -1.22 \\
\hline & 6 & 5.22 & 6.253 & -1.033 \\
\hline & 7 & 5 & 6.173 & -1.173 \\
\hline & 8 & 5.087 & 6.26 & -1.173 \\
\hline & 9 & 5.32 & 6.053 & -0.733 \\
\hline & Average & 5.1254 & 6.1918 & -1.0664 \\
\hline \multirow{5}{*}{ Responsiveness } & 10 & 5.293 & 6.013 & -0.72 \\
\hline & 11 & 5.313 & 6.02 & -0.707 \\
\hline & 12 & 5.493 & 6.193 & -0.7 \\
\hline & 13 & 5.127 & 5.98 & -0.853 \\
\hline & Average & 5.3065 & 6.0515 & -0.745 \\
\hline \multirow{5}{*}{ Assurance } & 14 & 5.173 & 5.967 & -0.794 \\
\hline & 15 & 5.367 & 6.12 & -0.753 \\
\hline & 16 & 5.513 & 6.081 & -0.568 \\
\hline & 17 & 5.413 & 6.247 & -0.834 \\
\hline & Average & 5.3665 & 6.10375 & -0.73725 \\
\hline \multirow{6}{*}{ Empathy } & 18 & 4.933 & 5.939 & -1.006 \\
\hline & 19 & 5.48 & 5.94 & -0.46 \\
\hline & 20 & 5.387 & 5.787 & -0.4 \\
\hline & 21 & 4.967 & 6.02 & -1.053 \\
\hline & 22 & 5.073 & 6.153 & -1.08 \\
\hline & Average & 5.168 & 5.9678 & -0.7998 \\
\hline Total Average & & 1.2 & 1.37 & -0.17 \\
\hline
\end{tabular}

Table 6 shows the comparison between the average score of the respondents between the two sets of variables viz. the perception and the expectation. There were five factors under each one of factors namely tangibles, reliability, responsiveness, assurance, and empathy. The total number of items were 22 . To analyse the differences, the mean for each item was calculated for both the sets of variables, then the difference between them was found between the two means of the corresponding factor responses. Total average score differences between the two questionnaires were in favour of the respondents' expectations about Omantel services.

The highest difference between the two questionnaires was in the reliability factor as the difference between total averages was 1.07 in favour of the expectation and this denoted that respondents' expectations about Omantel reliability services were more significant than their perceptions. On the other hand, the least difference between the two sets of variable was in the tangibles factor as the difference between total averages was 0.40 in favour of the expectation questionnaire and this denoted that the respondents' expectations about Omantel's tangibles was slightly significant than their perceptions.

The other differences between the two sets of variables were similar to each other as they were all factors in favour of the expectation. In the responsiveness dimension, the overall average response of both were in 
favour of expectation, with an average difference between the overall averages 0.74 whereas assurance factors have an average score difference between the total averages was 0.737 and the total average of both the responses was in favour of expectation. Also, the questionnaires' responses were in favour of expectations in the Empathy factor, and the total averages was 0.74 . The respondent's expectation of Responsiveness, Assurance, and Empathy factors have been negative with their expectations.

In conclusion, the total average of both the sets of responses was in favour of expectation as the average score of difference between the total averages was 0.17 . This inferred that the respondents' expectations about the quality of services of Omantel was negative with that of their expectations.

\section{Discussion}

To satisfy the customers, it is necessary to offer the best services. The total average score differences between the two sets of variables were favourable to the expectations of the respondents regarding Omantel services. In both the sets of variables, the outcomes showed that the reliability factor influenced customer satisfaction. So, the factor of expectations suggested that the aspirations of Omantel reliability services respondents were more important than their perceptions. While the least averages factor - Tangibility factor have not much influenced the customer satisfaction in the selected company of telecom sector of the sultanate of Oman i.e. Omantel. The other three dimensions' assurance, empathy, and responsiveness were similar to each other because they were all factors in support of the factors of expectations. This indicated that the expectation of the respondents about the Omantel services was negative with their expectations. Hence, the findings of this research will be beneficial for the telecom sector management to enhance the quality of their service because happy customers not only add loyalty but also enhance the company's reputation.

\section{Conclusion}

From the above, it can be seen that not all SERVQUAL dimensions affect customers while reliability is the most different one in both perceptions and expectations in comparison to others especially the tangibles which is the factor with least difference. The result of the study will help Omantel Company to develop strategy for the service quality in the areas of assurance, empathy, and responsiveness. Understanding how consumers view the quality of the service and being able to quantify the expected service will help business professionals quantitatively and qualitatively.

Measuring the standard of service will provide detailed data that can be used in quality management. Omantel Company should focus on providing high-quality service to the satisfaction of the customers which can be identified using SERVQUAL methodology as a technique in determining the difference between consumer preferences and perceptions about the quality of services by measuring the effect of five dimensions - tangibles, reliability, responsiveness, assurance, and empathy on customer satisfaction. Assessing the quality of service and a deeper understanding of how different measurements influence the overall quality of service will enable organizations, Omantel Company in particular, to plan the service delivery process efficiently.

\section{Recommendations}

The telecommunication companies are characterized as highly competitive and regulated but they need to analyse more to improve trust and loyalty of the customers and provide high-quality services to the customers. Therefore, telecom companies should focus in improving organizational performances.

1. Telecommunications companies must strategically plan to earn the trust of customers through proper prediction of customer needs and their requirements.

2. The employees of the company must treat their clients honestly and sincerely, listening to customer needs. Responding to the feedback is the best way to earn the customers' trust. Constant communication with clients, serving the customers in an efficient way and solving their problems in a short period only will improve service quality.

3. Omantel Company should focus on improving customer relationships by developing a competitive policy in the telecom market compared to other telecommunication companies.

4. The development of cadres for the talented employees working in the company, so, telecom service the management of the company should care for the development of employee skills and expertise in providing quick and efficient services.

5. Focus on providing digital channels for commercial subscribers in addition to developing services and offers.

6. Provision of protection for customer transactions, the extension of working hours at the weekend through the availability of customer support centres. 


\section{References}

1. Anjum, U., Aftab, J., Sultan, Q., \& Ahmed, M. (2016). Factors affecting the service quality and customer satisfaction in telecom industry of Pakistan. International Journal of Management, Accounting, and Economics, 3(9), 509-520.

2. Castelnovo, P., Del Bo, C.F. \& Florio., M. (2019). Quality of institutions and productivity of StateInvested Enterprises: International evidence from major telecom companies. European Journal of Political Economy, 58, 102-117. https://doi.org/10.1016/j.ejpoleco.2018.10.005

3. Dayani, A., \& Beheshti, S. K. (2015). Evaluation of Quality of Service to Customers of Telecommunications Company in Isfahan with Gap Analysis: Model Gam. Oman Chapter of Arabian Journal of Business and Management Review, 34(2603), 1-5.

4. Foster, S. T. (2000). Managing quality. England: Prentice Hall.

5. Hosseini, S., Bahreini, Z., \& Ziaei, B. (2013). Providing a multidimensional measurement model for assessing mobile telecommunication service quality (MS-Qual). 7-29.

6. Al Jabri, H. A., Al-Badi, A. H. \& Ali, O. (2017). Exploring the usage of big data analytical tools in telecommunication industry in Oman. Information Resources Management Journal, 30(1), 1-14. http://doi.org/10.4018/IRMJ.2017010101

7. Khan, N., Akram, M. U., Shah, A., \& Khan, S. A. (2017, November). Important attributes of customer satisfaction in telecom industry: A survey based study. In 2017 th IEEE International Conference on Engineering Technologies and Applied Sciences (ICETAS) (pp. 1-7). IEE.

8. Mpwanya, M. F., \& Letsoalo, M. E. (2019). Relationship between service quality, customer satisfaction, and behavioral intentions in South Africa's mobile telecommunication industry. African Journal of Business and Economic Research, 14(2), 67-89. https://doi.org/10.31920/1750-4562/2019/14n2a4

9. Newton, S., \& Ragel, V. R. (2017). The effectiveness of relational bonds on customer loyalty mediated with customer satisfaction: telecommunication industry, Batticaloa. Asian Journal of Economics, Business, and Accounting, 4(3), 1-11. https://doi.org/10.9734/AJEBA/2017/36550

10. Olatokun, W. M., \& Ojo, F. O. (2016). Influence of service quality on consumers' satisfaction with mobile telecommunication services in Nigeria. Information Development, 32(3), 398-408. https://doi.org/10.1177/0266666914553316

11. Palladan, A. A., \& Ahmad, M. A. (2019). Leveraging Customers Loyalty in Telecommunication Industry: The Role of Service Quality and Customer Satisfaction a PLS Approach. International Journal of Marketing Research Innovation, 3(1), 1-10. https://doi.org/10.46281/ijmri.v3i1.249

12. Rahhal, W. (2015). The effects of service quality dimensions on customer satisfaction: An empirical investigation in Syrian mobile telecommunication services. International Journal of Business and Management Invention, 4(5), 81-89.

13. Santouridis, I. \& Trivellas, P. (2010). Investigating the impact of service quality and customer satisfaction on customer loyalty in mobile telephony in Greece. The TQM Journal, 22(3), 330-343. https://doi.org/10.1108/17542731011035550

14. Shafei, I., \& Tabaa, H. (2016). Factors affecting customer loyalty for mobile telecommunication industry. EuroMed Journal of Business, 11(3), 347-361. https://doi.org/10.1108/EMJB-07-2015-0034

15. Singh, G., \& Kumar, N. (2014). The Impact and Assessment of customer satisfaction \& loyalty on CRM. Arth Anvesan, 9(1), 70-89.

16. Urban, W. (2009). Service Quality Gaps and their role in service enterprises development. Technological and Economic Development of Economy, (4), 631-645.

17. Wang, Y. L., Tainyi, L. U. O. R., Luarn, P., \& Lu, H. P. (2015). Contribution and Trend to Quality Research-a literature review of SERVQUAL model from 1998 to 2013. Informatica Economica, 19(1), 3445. http://doi.org/10.12948/issn14531305/19.1.2015.03

18. Yang, S. (2015). Understanding B2B customer loyalty in the mobile telecommunication industry: a look at dedication and constraint. Journal of Business \& Industrial Marketing, 30(2), 117-128. https://doi.org/10.1108/JBIM-05-2013-0105

19. Yarimoglu, E. K. (2015). A Review of Service and E-Service Quality Measurements: Previous Literature and Extension. Journal of Economic \& Social Studies, 5(1), 169-200.

Copyright: () 2021 by the authors. Licensee Global Scientific Publications, Oman.

This work is licensed under a Creative Commons Attribution-ShareAlike 4.0 International License.

This is an open-access journal and the articles published in this journal are distributed under the terms of CC-BY-SA. 